\title{
From English worldwide to graveyard humour
}

As with previous issues, articles in English Today 97 cover a wide variety of topics, ranging from English in Europe and the US to African Englishes and English in China and Korea. At the descriptive level, the article by Christiane Meierkord provides a number of fascinating insights into the linguistic ecology of Kenya, as well as a detailed account of Engsh, a mixed language that combines elements of local languages, English, and American slang. K. Aaron Smith's article on the be fixing to structure traces the trajectory of this construction from its origins in eighteenth century US English to its contemporary use on the internet. Daniel Schreier's article offers both a theoretical as well as a descriptive discussion of such 'lesser-known' varieties as St Helenian English. Andrew Sewell's article on the Hong Kong English accent provides a survey of recent work from a number of perspectives, while also considering the importance of both 'intelligibility' and 'acceptability' in legitimating the recognition of local accents of English.

By contrast, both Emily Fong's and Alexander Onysko's articles deal with discourses about English, albeit in two very different settings, the first in postOlympics China, and the second in con- temporary Germany. Emily Fong's article focuses on the extent to which English in China is officially perceived as a 'modern skill', as well as attitudes to 'China English' among overseas Chinese students. Alexander Onysko presents an overview of recent research on English borrowings or 'anglicisms' in Germany, presenting an original analysis of the various ('purist' and 'non-purist') conceptualizations of anglicisms that are found in the German press. Jin-Kyu Park's article on 'English fever' in South Korea also touches on debates about English in Korean society, while at the same time documenting the current and somewhat worrying fad for 'study-abroad' schemes for very young children.

On another - rather lighter - note, Susan Purcell's and Alex Tulloch's articles deal with words. Susan Purcell's article on Hobson-Jobson reminds us once again of the importance of this early dictionary of Indian English. Finally, Alex Tulloch, now a regular contributor, discusses the Greek origins of a number of familiar English words, even providing a twist of graveyard humour in his analysis of the lexicon of Greek theatre.

The Editors

The editorial policy of English Today is to provide a focus or forum for all sorts of news and opinion from around the world. The points of view of individual writers are as a consequence their own, and do not reflect the opinion of the editorial board. In addition, wherever feasible, ET generally leaves unchanged the orthography (normally British or American) and the usage of individual contributors, although the editorial style of the journal itself is that of Cambridge University Press. 